\title{
FAMÍLIA, MODERNIZAÇÃO CAPITALISTA E DEMOCRACIA: retomando alguns marcos do antigo debate sobre as transformações da família no Brasil
}

\author{
Maria Fatima Araújo*
}

\section{Resumo}

O artigo analisa as transformações da família no Brasil ocorrido sob a influência da modernização capitalista e dos movimentos sociais libertários em defesa da democracia, da liberdade e igualdade, reconhecimento das diferenças e dos direitos humanos e individuais. De forma não exaustiva procura recuperar alguns dos principais marcos dessas mudanças, com destaque para o período pós-1964, quando se deu a aceleração do processo de modernização e a revolução de valores que levou à crise da família nos anos 1970 e à sua passagem, nas décadas seguintes, do tradicional modelo hierárquico e autoritário para outras formas de organização familiar mais democráticas e igualitárias.

Palavras-chave: Família. Modernização capitalista. Democracia. Feminismo

Instituição historicamente determinada, a família acompanha as mudanças da sociedade incorporando novos valores, funções e formas de organização, de acordo com as ideologias dominantes e necessidades sociais, culturais, econômicas e políticas de cada época. Com base nessa compreensão histórica este artigo analisa as transformações da família brasileira, destacando duas principais influências: a modernização capitalista, em especial o projeto modernizador implantando pelo governo pós-64 que, apesar de conservador e repressor, promoveu grandes transformações sociais, econômicas e culturais; e a expansão dos movimentos sociais libertários que ganharam corpo nos anos 1970, embalados pelos

\footnotetext{
* Psicóloga (UFC), Mestrado em Psicologia Clínica(PUC/SP), Doutorado em Psicologia Social(IPUSP); Pós-doutorado em Saúde Coletiva(FMUSP). Professora do Prog. de Pós-Graduação em Psicologia da UNESP/Assis; Pesquisadora do Núcleo de Estudos Violência e Relaçãoes de Gênero (UNESP/Assis). Email: fatimaraujo@uol.com.br.
} 
ideários democráticos e feministas em torno da luta pela liberdade e igualdade, reconhecimento das diferenças e dos direitos humanos e individuais. Busca recuperar o contexto em que essas mudanças ocorreram e o seu impacto na vida social e familiar, sobretudo na transformação dos valores e comportamentos que marcaram a transição do tradicional modelo de família patriarcal, hierárquico e autoritário para uma organização familiar mais igualitária e democrática. A chamada “família igualitária” que emergiu nos anos oitenta como um novo ideal de família, buscado principalmente pelos segmentos médios urbanos mais intelectualizados e identificados com as ideologias modernizadoras.

No desenvolvimento do texto fazemos uma breve contextualização do desenvolvimento do capitalismo no Brasil sempre buscando apreender a intrínseca relação entre as mudanças sociais, culturais e econômicas trazidas pelo processo de modernização capitalista e as mudanças da família em diferentes momentos históricos.

A relação modernidade e capitalismo é um tema já abordado por muitos autores, entre os quais Marx e Engels. No "Manifesto do Partido Comunista” eles dizem: "tudo que era sólido e estável evapora-se, tudo que era sagrado é profanado, e os homens são, finalmente, obrigados a encarar com serenidade suas condições de existência e suas reflexões recíprocas” (MARX e ENGELS, 1990, p79). Essa imagem retrata a metamorfose de valores, o dinamismo e a fluidez da sociedade burguesa capitalista, onde os indivíduos são constantemente submetidos a novas situações.

A discussão sobre o processo de modernização é antiga e ainda hoje se alimenta de grande polêmica (SHINN, 2008). Segundo Habermas (1983), não se pode separar modernidade cultural e modernidade da sociedade. A cultura intervém apenas de modo indireto e mediato. O modernismo cultural oculta à relação entre a modernização capitalista da economia e da sociedade e as mudanças produzidas na cultura. É a modernização social que cria as condições para a heterogeneidade cultural, pluralidade de valores, formas alternativas de sociabilidade, desenvolvimento da subjetividade etc. É essa perspectiva que orienta a análise aqui esboçada.

\section{Capitalismo e modernização no Brasil}

O desenvolvimento do capitalismo no Brasil já foi exaustivamente analisado sob diferentes perspectivas (FERNANDES, 1981; ORTIZ, 1988; SKIDMORE, 1979; FAUSTO, 1981; FURTADO, 1982) e não é o caso de retomá-las aqui. A referência a elas é apenas para 
identificar como as mudanças sociais, culturais, econômicas e políticas trazidas pela modernização capitalista influenciaram nas transformações da família.

O processo de modernização no Brasil teve, ao longo da história, uma característica essencialmente conservadora. O termo “modernização conservadora” é comumente usado para retratar situações em que elementos modernizadores são introduzidos fora dos contextos da modernidade capitalista ou, de uma forma conceitualmente mais precisa, para caracterizar revoluções burguesas que acontecem pelo "alto" ${ }^{1}$, ou seja, revoluções conservadoras que não rompem com a velha ordem política e social. A origem do conceito é atribuída a Barrington Moore Junior (1975), que o empregou para retratar o desenvolvimento do capitalismo na Alemanha e no Japão. Nesses países, o processo de industrialização resultou de revoluções burguesas vindas de cima, resultantes de pactos políticos estabelecidos entre a burguesia e as forças feudais. No Brasil, o processo ocorreu de forma semelhante ${ }^{2}$, embora com características distintas. Aqui as revoluções sempre se deram pelo “alto”, sob a liderança das elites, sempre preocupadas em garantir seus interesses (DOMINGOS, 2002). Essa tendência conservadora marcou o desenvolvimento do capitalismo no Brasil desde a velha República (REIS, 1982), manteve-se ao longo de todo o século XX, nas revoluções de 1930 e 1964 (WERNECK VIANA, 1976), e só começa a se esgotar no final da década de 1970 com a pressão dos movimentos sociais pela retomada da democracia no país. Mesmo assim, ainda de forma muito tímida. Como observa Coutinho (1992), por mais que a transição democrática dos anos 1980 se caracterizasse pelo protagonismo popular fazendo pressões de "baixo para cima”, as negociações entre as elites dominantes prevaleciam sobre as demandas populares.

Segundo Florestan Fernandes (1981), o Estado Nacional independente era liberal somente nos seus fundamentos formais. Na prática, era instrumento de dominação, organizado para atender aos interesses econômicos, sociais e políticos dos estamentos senhoriais. Portanto, não produziu mudanças reais nas relações de produção. A autonomização do país iniciou-se como um fenômeno especificamente político, não resultou de uma revolução econômica nem de rupturas com o passado. Ao contrário, consolidou as funções da lavoura como polo dinâmico da economia interna, com a produção voltada para a exportação. A extinção do Estatuto Colonial não resultou da evolução histórica do país, senão

\footnotetext{
${ }^{1}$ Revolução pelo “alto” é uma revolução “passiva” no sentido gramsciano. Ela difere da revolução popular, “jacobina”, que, por ser realizada de baixo para cima, rompe radicalmente com a velha ordem política e social. Uma revolução passiva, segundo Gramsci (apud COUTINHO, 2007), implica sempre a presença de dois momentos: o da "restauração" (trata-se sempre de uma reação conservadora à possibilidade de uma transformação efetiva e radical proveniente “de baixo”) e da "renovação” (no qual algumas das demandas populares são satisfeitas "pelo alto”, através de “concessões” das camadas dominantes).

${ }^{2}$ Vale lembrar aqui a emblemática frase "Façamos a revolução antes que o povo a faça”, atribuída ao governador mineiro Antonio Carlos Ribeiro de Andrade durante a Revolução de 1930.
} 
do resultado de pressões externas, pois interessava ao neocolonialismo. Os senhores rurais continuaram com a mesma mentalidade: exportavam o que produziam e importavam o que consumiam. Os modelos econômicos transplantados mantinham e intensificavam a economia dependente, não tinham por meta criar processos de desenvolvimento interno análogo ao que se produzia nas economias centrais. Com o tempo, a abolição dos escravos se fez necessária para acabar com os entraves da ordem escravocrata e senhorial à expansão do capitalismo. A consolidação do capitalismo provocou a ruptura da homogeneidade da aristocracia rural e possibilitou o surgimento de um setor novo ligado à economia urbana e com ele novos tipos urbanos, os burgueses (comerciantes, especialistas em transações comerciais e financeiras) e os estamentos médios (funcionários, militares e profissionais liberais). Enquanto a aristocracia rural se interessava pelo comércio exterior, os burgueses em ascensão investiam no comércio interno. Esse espaço foi ocupado principalmente pelos imigrantes, que encontraram nesse setor em expansão a oportunidade de enriquecer e ascender socialmente. O imigrante encarnou a mentalidade competitiva própria do capitalismo. Sua preocupação era com a acumulação do capital com fins imediatistas, sem nenhuma preocupação com a nação propriamente dita. Pioneiros do capitalismo industrial, os imigrantes foram agentes de desagregação da ordem senhorial. Portanto, a burguesia no Brasil não teve um papel revolucionário, ao contrário, evoluiu junto com a aristocracia rural e não contra ela. $\mathrm{O}$ desenvolvimento do comércio e o crescimento da economia urbana tiveram que se adaptar às estruturas da ordem social escravocrata. A economia urbana industrial não tinha porta-vozes representativos. Foi necessária uma acomodação até que ela se firmasse como importante setor do mercado capitalista.

Florestan Fernandes (1981) divide o desenvolvimento do capitalismo no Brasil em três fases: a primeira, inicia-se com a transição para o neocolonialismo. Vai da abertura dos portos até a $6^{\text {a }}$ década do século XIX com a crise do sistema de produção escravagista. É a fase da eclosão do mercado capitalista especificamente moderno. A segunda é a fase da formação e expansão do capitalismo competitivo, onde se dão a consolidação e disseminação do mercado como fator de diferenciação do sistema econômico. Compreende tanto o período de consolidação da economia urbano-industrial, quanto à primeira transição industrial verdadeiramente importante. Vai da $6^{\text {a }}$ década do século XIX até a década de 50 do século XX. E a terceira, é a fase da irrupção do capitalismo monopolista. Caracteriza-se pela reorganização do mercado e do sistema de produção, através de operações comerciais financeiras e industriais de "grande corporação" (predominantemente estrangeira, mas 
também estatal ou mista). Embora as tendências para essa evolução sejam anteriores, ela só se acentua no fim da década de 50 e só adquire o caráter estrutural após a revolução de 1964.

\section{Modernização e Família: do período colonial à primeira metade do século XX}

A forma de organização da família patriarcal rural brasileira resultou da adaptação do modelo de família, trazido pelos portugueses, ao modelo sócio-econômico vigente no país. Os primeiros colonos que aqui chegaram estabeleceram uma ordem econômica e social de acordo com seus interesses, desde que não interferisse nos interesses de Portugal. Na prática, os proprietários de terra reinaram sozinhos nos três primeiros séculos de colonização. A Coroa interferia somente nos casos de excesso. Desta forma, de acordo com Costa (1989), a família latifundiária acumulou uma enorme massa de poder. Funcionava como um verdadeiro clã: o pater familias concentrava as funções militares, empresariais e afetivas; sob seu poder e proteção viviam sua mulher, filhos, parentes, escravos e agregados.

Não há consenso entre os pesquisadores quanto à predominância no Brasil Colônia deste modelo de família patriarcal rural extensa, tão bem descrito por Gilberto Freire (2008). Segundo Samara (1987), ele era encontrado apenas entre uns poucos senhores de engenho do Nordeste; no sul do país, nos séculos XVIII e XIX, predominava um modelo de família com estrutura mais simplificada e menor número de componentes. Contudo, na opinião de Roberto Da Matta (1987), independente da existência ou não de outras formas de família entre as diferentes classes sociais, o modelo patriarcal oferecia um paradigma social para toda a população. Era uma forma dominante de constituição social e política, embora não fosse a única. Em termos de ordenamento social, era inegável o seu poder no controle dos recursos da sociedade.

A família patriarcal rural começa a mudar com a chegada da Corte Portuguesa, em 1808, quando elementos culturais modernizadores são introduzidos na sociedade e se estabelece uma nova ordem social e política. A instalação da família real no Rio de Janeiro acelerou o processo de modernização e urbanização da cidade, a população aumentou consideravelmente e seus novos habitantes - aristocratas, diplomatas, comerciantes estrangeiros - passaram a impor novas formas de sociabilidade, hábitos e costumes, que passaram a ser imitados pela população local. O modelo de família moderna, gestado na Europa, no seio da burguesia, foi introduzido na sociedade brasileira, apesar de ainda predominantemente latifundiária e escravagista. A família burguesa apresentava-se com uma 
estrutura reduzida, composta pelo casal e filhos, e uma organização hierárquica baseada em uma rígida divisão de papéis sexuais e separação dos espaços público e privado. Ela também instituiu um conjunto de novos valores e atitudes em relação à intimidade, à vida privada, ao relacionamento familiar e à educação dos filhos. Foi, sem dúvida, uma modernização “fora de lugar" 3 .

A incorporação do modelo burguês ocorreu paralelamente ao processo de urbanização, e, coube aos médicos higienistas auxiliarem as famílias na mudança dos costumes, valores e reorganização das relações de poder. Segundo Costa (1989), a ação dos higienistas dirigia-se às famílias de elite e incluía uma estratégia de "nacionalização”. Visava modificar a conduta física, intelectual, moral e sexual de seus membros em função dos interesses do Estado. Tinha como objetivo minimizar o poder do patriarca e produzir uma norma familiar capaz de formar cidadãos individualizados, domesticados e colocados à disposição da cidade, do Estado e da pátria. Em nome da saúde, os higienistas foram, gradativamente, domesticando a família à ordem médica e às ideologias burguesas. Dentre elas a ideologia do amor materno, que enaltecia o papel da mulher como mãe dedicada ao lar e aos filhos; e a ideologia do amor romântico, que reunia amor, sexo e casamento ${ }^{4}$. Com isso, o direito à escolha do parceiro ${ }^{5}$ passou a ser valorizado, assim como o relacionamento afetivo entre pais e filhos. A ideia de “família amorosa”, baseada no prazer de procriar e cuidar dos filhos como um ato de amor, passou a ser alimentada como o ideal de família. Assim, a tradicional família patriarcal rural e extensa foi gradativamente, ao longo do século XIX, absorvendo os valores típicos da sociedade burguesa, mas mantendo sua matriz patriarcal, hierárquica e autoritária reforçada pelos ideários cristão e positivista.

Segundo Riolando Azzi (1987), o pensamento católico e o pensamento positivista tiveram uma enorme influência na formação dos valores e mudanças operadas na família brasileira no período de 1870 a 1950. Ambos defendiam o modelo de família hierárquica com papéis, posições e comportamentos bem definidos: o homem - marido, pai e provedor - era o chefe da família; à mulher, esposa e mãe, cabia o cuidado do lar, procriação e educação dos

\footnotetext{
${ }^{3}$ Sobre isso ver análise de Roberto Schwarz (1988) sobre "as ideias fora do lugar” a respeito da desadequação das ideias liberais importadas da Europa à realidade brasileira do século XIX. E também Kátia Muricy (1987) sobre as referências na literatura de Machado de Assis à forma “desajeitada” com que as familias de elite incorporavam os novos hábitos e valores introduzidos pela corte portuguesa.

${ }^{4}$ A nova moral burguesa, legitimada pela tradição cristã, condicionou o exercício do sexo ao casamento, instituindo assim a monogamia formal que na prática só se aplicava à mulher.

${ }^{5} \mathrm{Da}$ antiguidade à média idade média, pelo menos, eram os pais que cuidavam do casamento dos filhos. $\mathrm{O}$ amor individual no sentido moderno de consensualidade, escolha e paixão amorosa não existia no casamento - em geral era vivenciado nas relações de adultério. Foi a ordem burguesa que instituiu o ideal do amor romântico reunindo sexo, amor e casamento (CERRONI, 1975).
} 
filhos, sendo valorizada por sua submissão e fidelidade ao marido; e os filhos deviam ser submissos e obedientes aos pais. A influência dessas duas correntes de pensamento, com forte tendência conservadora, predominou até a primeira metade do século $\mathrm{XX}$, quando o pensamento liberal ganha força com o impulso da modernização capitalista. Sob a influência das ideias liberais que, dentre outras coisas, combatia o autoritarismo da família, incentivava a participação das mulheres na vida social e criticava a rigidez na educação ministrada nos colégios católicos, a família brasileira começa a assumir um caráter mais progressista e os padrões conservadores que a dominaram por mais de um século começam a entrar em crise.

\section{A aceleração do processo de modernização no período pós-64: consequências econômicas e políticas e seu impacto na vida social e familiar}

Conforme já apontado, o desenvolvimento do capitalismo no Brasil ganhou impulso na década de 1930, expandiu-se na década de 1950 e se acelerou na década de 1960, especialmente a partir de 1964. Divisor de águas na história do Brasil, segundo SKIDMORE (1979), o golpe militar de 1964 teve um significado político e econômico dentro da conjuntura política mundial naquele momento. Diante da ameaça de expansão de movimentos democráticos, as forças imperialistas passaram a exigir “estabilidade política” dos países periféricos em troca de ajuda econômica e financeira. O projeto modernizador implantado pelo governo militar atendia a essa exigência: defendia a estabilidade da ordem e o desenvolvimento com segurança. Tinha como meta uma modernização conservadora da economia baseada em uma concepção de progresso alcançado através do trabalho, da disciplina e submissão ao Estado de acordo com a ideologia de segurança nacional. A ênfase no desenvolvimento econômico levou o país, no final da década de 1960 e início da década de 1970, a um acelerado processo de crescimento caracterizado como o "milagre brasileiro" (PEREIRA, 1985). Novas indústrias foram instaladas no país produzindo a expansão do setor industrial, a diversificação da produção, incentivo à iniciativa privada e grande estímulo ao consumo. Com isso, novas oportunidades de trabalho foram criadas favorecendo o processo de ascensão social em uma determinada parcela dos setores médios da população.

Entretanto, paralelamente à euforia desenvolvimentista instalou-se uma política repressiva e autoritária que invadiu todos os setores da sociedade, reprimindo e silenciando qualquer manifestação que ameaçasse a nova ordem. Em nome do progresso, da disciplina e da segurança nacional justificavam-se todos os atos de violência e arbítrio. Os segmentos 
democráticos que tentaram resistir foram totalmente reprimidos pelo AI-5 ${ }^{6}$. O silêncio compulsório implantado por este Decreto provocou um imenso vazio cultural na sociedade brasileira que se estendeu por uma longa década.

Na realidade, o projeto modernizador implantado pelo governo militar baseava-se em um modelo de desenvolvimento dependente, voltado para os interesses do monopólio interesses do capital estrangeiro e dos grandes grupos nacionais - mantinha um padrão de desenvolvimento industrial para atender às demandas do mercado internacional. Assim, o "milagre” teve consequências desastrosas: aumentou consideravelmente a concentração de renda (e das riquezas) nas mãos de uma minoria, acentuou as desigualdades regionais, e instaurou um processo de pauperização sem precedentes no mundo contemporâneo (FURTADO, 1982).

Com a crise do "milagre”, as resistências democráticas começaram a se organizar e se fortaleceram a partir da eleição de 1974. A insatisfação geral da população diante da escalada inflacionária, perda do poder aquisitivo e empobrecimento gradativo, expressou-se nas urnas em 1974 através da preferência do povo pelo partido de oposição (O MDB) e dos votos nulos. Diante disso e com o governo militar já em declínio, o presidente Geisel propôs uma abertura "lenta, gradual e segura” que foi de 1974 a 1985, quando o governo Figueiredo viabilizou a transição para a “nova república” com a eleição de Tancredo Neves e José Sarney pelo Colégio Eleitoral, em 15 de janeiro de 1985.

Essa transição resultou de intensa negociação entre as forças políticas, tendo em vista as condições históricas que se apresentavam naquele momento (MENDONÇA, 2005). A mobilização do povo pelas "Diretas Já” e o anseio geral de mudança levou à formação de uma grande aliança que se sobrepunha às diferenças e escamoteava os processos que favoreciam a manutenção no poder das forças conservadoras. Foi, portanto, uma transição conservadora, como observa Coutinho (1992), ainda que resultante de ampla mobilização da sociedade. Deu-se em meio a uma imensa crise econômica. A dívida externa do país era a maior do mundo capitalista; a economia nacional, apesar de ser a oitava do mundo, era dependente financeira e tecnologicamente das relações internacionais, e o país vivia uma situação de grande recessão e depressão alimentada por uma galopante inflação e enormes problemas sociais (OLIVEIRA, 1985).

\footnotetext{
${ }^{6}$ Ato Institucional que deu poderes absolutos ao presidente da República para cassar mandatos, suspender direitos civis e políticos de qualquer cidadão, proibir manifestações populares, impor censura prévia a jornais, revistas, livros, peças de teatro e músicas. Instituído pelo presidente Costa e Silva, em 1968, vigorou até 1978 quando foi revogado pelo presidente Geisel.
} 
Após a dramática morte de Tancredo Neves, antes mesmo de tomar posse do cargo $^{7}$, José Sarney assumiu a presidência da república e deu início à transição democrática. Seu governo (1985-1990) foi marcado pela ineficiência dos planos econômicos (Cruzado, em 1986; Bresser, em 1987; e Verão, em 1989), principais saídas buscadas para conter a inflação. Mas avançou em termos políticos. Intensificou o processo de democratização com ações importantes, como a revogação de todas as medidas que limitavam o direito ao voto e organização política, e a convocação da Assembléia Constituinte que elaborou a Constituição de 1988, restabelecendo os direitos democráticos, incluindo as eleições diretas para presidente (KINZO, 2001).

Foi neste cenário que se gestou o processo de fortalecimento das instituições democráticas e de mobilização da sociedade civil em defesa da democracia como estratégia fundamental para mudar a realidade política, econômica e social do país. Tais conquistas e anseios embora contemplados na Constituição de 88 só começaram a se viabilizar a partir dos anos 1990.

É importante destacar que apesar das dramáticas consequências econômicas (crise do “milagre”) e políticas (autoritarismo e repressão às liberdades e direitos democráticos) o projeto modernizador implantado pelo governo militar, trouxe mudanças importantes, como a expansão da industrialização e urbanização, avanço da tecnologia, difusão dos meios de comunicação de massa, desenvolvimento da indústria de serviços que promoveu a racionalização de muitas atividades domésticas, desenvolvimento da indústria cultural e consolidação do mercado de bens e consumo. Tais mudanças tiveram um enorme impacto na vida social e familiar, especialmente sobre as camadas médias urbanas ${ }^{8}$, segmentos mais expostos a veículos e ideologias modernizadoras (VELHO, 1981; SALEM, 1986; FIGUEIRA, 1987). Esse impacto pode ser observado tanto no aspecto econômico - mudança no padrão de consumo, aspirações de ascensão social - quanto no aspecto comportamental mudança de hábitos e valores.

Com a expansão do mercado de bens e consumo, uma ética consumista passou a dominar toda a vida pessoal e familiar. Transformada em importante setor do mercado e alvo da indústria cultural, a família tornou-se grande consumidora de bens e serviços em todas as áreas - saúde, lazer, cultura, educação, psicologia, seguros, meios de comunicação etc. A imagem da família consumista passa a ser veiculada pela indústria cultural como sinônimo de

\footnotetext{
${ }^{7}$ Tancredo Neves adoeceu em 14 de março de 1985 e faleceu em 21 de abril de 1985, 39 dias após ser eleito.

${ }^{8}$ Há um certo consenso entre os autores em incluir nessa categoria profissionais liberais e demais trabalhadores não manuais assalariados ou não.
} 
“família moderna”, sinal de ascensão social, status e prestígio. Uma série de serviços e aparatos técnico-sociais (berçários, creches, maternais, alimentos industrializados, eletrodomésticos) foram criados para simplificar o trabalho doméstico e familiar. Assim, muitas das funções e atividades da família foram descentralizadas e disseminadas entre os agentes sociais criados pela indústria de serviços. Isso impulsionou o ingresso das mulheres no mercado de trabalho, tanto pelo aumento de oportunidades de trabalho criadas pelo desenvolvimento econômico e indústria de serviços (área que absorveu grande parte de mãode-obra feminina) quanto pela necessidade das famílias de manterem o padrão de consumo.

Neste processo, a televisão teve um papel fundamental na difusão da indústria cultural e de serviços, no fortalecimento da ética consumista e na produção de novas necessidades, valores, hábitos e costumes. Segundo Ortiz (1988), o desenvolvimento da televisão é o que melhor caracteriza o advento da indústria cultural no Brasil, especialmente a partir de 1965 quando se consolida como veículo de comunicação de massa e de integração nacional ${ }^{9}$ para difusão da indústria cultural ${ }^{10}$, ideologias e elementos modernizadores.

Dentro da programação a telenovela passou a ocupar um lugar importante na formação de novos hábitos, valores e mudanças de comportamentos sociais e familiares. Apresentada em capítulos diários e aperfeiçoada pela tecnologia e imagem a cores, ela contribuiu para consolidar o hábito de assistir televisão que logo se disseminou por todos os segmentos sociais.

Neste contexto, o ideário feminista ${ }^{11}$ foi também bastante explorado pela indústria cultural em representações da "mulher moderna”, passadas através de modelos de mulheres emancipadas, em novelas e seriados ${ }^{12}$; no cinema nacional ${ }^{13}$; em revistas femininas como Claudia, Nova, Ele e Ela (ALVES, 1973). Mas a assimilação dessas representações do “moderno" não ocorreu de forma imediata e tranquila, ao contrário provocou muita desorientação e conflito entre os valores tradicionais e modernos produzindo, segundo Figueira (1987), “formas reativas de modernização”. Na verdade uma “falsa modernização”,

\footnotetext{
${ }^{9}$ Viabilizado pelo sistema de redes que permitiu a interligação de todo o território nacional.

${ }^{10}$ Na verdade "a indústria cultural possibilitou uma integração nacional em termos mercadológicos [...] a ideia de nação integrada passa a representar a interligação de consumidores potenciais espalhados pelo território nacional (ORTIZ, 1988:155-165)

${ }^{11} \mathrm{O}$ movimento feminista irrompeu na Europa e nos estados Unidos nos anos 1960, no bojo de outros movimentos sociais libertários - contracultura, liberação sexual etc. No Brasil ele surgiu mais tardiamente e muito envolvido com luta pela Anistia, retomada da democracia do país e defesa dos direitos humanos.

${ }^{12}$ Um deles foi “Malu Mulher”, apresentado pela Rede Globo de 1979 a 1980. Protagonizado pela atriz Regina Duarte, abordava os dilemas e desafios enfrentados por uma mulher recém separada, com uma filha, na luta para refazer a sua vida. A personagem é apresentada como a “nova mulher”, moderna e independente que enfrenta muitos preconceitos em uma sociedade ainda em transição.

${ }^{13}$ Em expansão na década de 1970 com a ampliação da EMBRAFILME e desenvolvimento da indústria cinematográfica. (ORTIZ, 1988)
} 
uma vez que as pessoas passaram a adotar valores e comportamentos modernos sem qualquer processo de elaboração. Foi neste cenário que o psicologismo ${ }^{14}$ se expandiu no Brasil aumentando a busca por terapias (psicanalítica e de outras abordagens), por cursos de psicologia e formação analítica, e também a difusão da psicanálise nos meios de comunicação de massas, e valorização do discurso "psi” por determinados grupos pertencentes aos segmentos mais intelectualizados - classe média e pequena burguesia.

A falta de perspectiva política favoreceu o desenvolvimento de uma cultura individualista voltada para a individualidade e subjetividade individual, deslocando a busca da liberdade e igualdade - principais pilares da ordem burguesa - para o campo das relações pessoais e familiares. Com isso, as lutas pelas liberdades ficaram restritas à liberdade individual e sexual. Ao longo da década de 1970 o culto às drogas e à liberdade sexual ocupou o espaço do questionamento político entre os jovens, nos grandes centros urbanos. Impedidos ou distanciados de qualquer participação política eles passaram a investir na busca do prazer e na liberdade de experimentar novas formas de sociabilidade e relacionamentos afetivo-sexuais. Assim, tradicionais valores como virgindade feminina e casamento formal, pilares da moral familiar burguesa e cristã, foram totalmente invertidos. Não ser virgem, liberar-se sexualmente e morar junto sem casar tornaram-se sinônimo de comportamentos de vanguarda, especialmente entre os segmentos médios dos grandes centros urbanos (FIGUEIRA, 1987; QUINTEIRO, 1990; VELHO, 1985; ARAÚJO, 1993; HEILBORN, 2004; SALÉM, 2007).

Por outro lado, é bom lembrar que esse processo de liberação sexual e transformação dos valores tradicionais cultuados pela família burguesa, estava acontecendo também em outros países ocidentais, independente do regime de governo vigente, sob forte influência dos movimentos libertários - feminismo, contracultura, revolução sexual. De forma similar ao que aconteceu nesses países, também no Brasil a família tornou-se alvo de críticas e questionamentos, por sua tradição autoritária, conservadora e repressora. De instituição idealizada até os anos 1950, esteio da moral e dos bons costumes, ela passou a ser demonizada como lugar de opressão e violência contra mulheres e crianças. Assim, ao longo de toda a década de 1970 uma enorme crise de valores se instaurou na família obrigando-a rever seus padrões de moralidade, sexualidade, práticas educativas, papéis e relações de poder.

\footnotetext{
14 O termo é usado aqui para caracterizar o boom da psicanálise que ocorrer no Brasil na década de 70 e assim como a expansão dos cursos de psicologia (RUSSO, 1987)
} 


\section{Da família hierárquica e autoritária à família igualitária}

A crise vivida pela família na década de 1970 marcou a passagem do modelo hegemônico de família hierárquica e autoritária para uma organização familiar mais igualitária e democrática, modelo ideal que, a partir da década de 1980, passou a guiar as mudanças da família, conforme apontam inúmeros estudos (FIGUEIRA, 1987; ALMEIDA, 1988; ARAÚJO, 1993 e 2008; HEILBORN, 2004; SALEM, 2007).

Segundo Figueira (1987), as mudanças da família hierárquica para a família igualitária, nos anos 1980, eram visíveis nos marcadores de identidade. Na família hierárquica a identidade era posicional: todos se definiam por sua posição, sexo e idade. Havia ideias claras sobre o que era "certo" e "errado", assim como mecanismos sutis de controle dos comportamentos. Já na família igualitária a identidade era idiossincrática: homem e mulher passaram a se perceber como diferentes, mas iguais como indivíduos. As diferenças pessoais tornaram-se mais importantes que as diferenças sexuais, etárias e posicionais. Os sinais estereotipados da diferença homem /mulher começaram a desaparecer, assim como as fronteiras entre o “certo” e o “errado”. Aparentemente, na chamada família igualitária instaurou-se reino da pluralidade de escolhas, limitadas apenas pelo respeito à individualidade do outro. Mas tudo isso acontecia no plano do ideal, na prática a “família igualitária” se defrontava com muitos conflitos e contradições.

Pesquisas realizadas na década de 1990 (ARAUJO, 1993 e 1999) confirmaram essa tendência iniciada na década anterior. Entre os casais entrevistados ${ }^{15}$ havia uma preocupação visível, mais nos discursos que nas práticas, de se organizarem de forma mais igualitária e democrática, com uma divisão mais flexível de papéis e tarefas, valorização do diálogo, da liberdade e igualdade, respeito às diferenças e à individualidade. Mas todos apontavam a dificuldade em lidar com os dilemas e conflitos decorrentes da busca de igualdade e incorporação dos valores democráticos. Reconheciam que na prática cotidiana, na relação conjugal e principalmente na educação dos filhos, as condutas e comportamentos eram marcadas por uma enorme ambivalência entre valores modernos e tradicionais.

Todo esse processo de democratização da família ocorreu pari passu à retomada da democracia no país e expansão das conquistas feministas em torno da luta pela igualdade de gênero. A emancipação feminina propiciada pela profissionalização e ingresso da mulher no

\footnotetext{
${ }^{15}$ Casais jovens pertencentes à classe média paulistana, com filhos em idade escolar. Todos intelectualizados e identificados com o discurso "psi” e o ideário feminista. Ambos os cônjuges tinham formação superior trabalhavam na área de formação.
} 
mercado de trabalho favoreceu a reorganização dos papéis e relações de poder dentro da família, e, também o surgimento de novos arranjos conjugais e familiares. Dentre eles as chamadas famílias monoparentais, constituídas por um dos genitores e os filhos; e as famílias reconstituídas, compostas por casais divorciados com ou sem filhos de outros casamentos. Esses dois arranjos cresceram muito no país a partir dos anos 1980, impulsionados pela lei do divórcio que favoreceu o reconhecimento legal e social de novas formas de família. Um outro arranjo, também em crescimento na última década, segundo dados do IBGE, é o de famílias sem filhos, ou família conjugal, constituída apenas pelo casal. De acordo com a Pesquisa Nacional por Amostra de Domicílios (PNAD) de 2008, mais de dois milhões de casais no país não têm filhos, embora marido e mulher tenham condições de tê-los. Os dados apontam que entre 1998 e 2008, esse tipo de família aumentou de 3,2\% para 5,3\%. Inúmeras pesquisas apontam o crescimento dessa tendência também em outros países ocidentais (RIOS e GOMES, 2009). Entre as motivações mais frequentes apontadas pelos casais que optam por esse arranjo familiar (família conjugal) estão a ausência de desejo pela maternidade e/ou paternidade, maior investimento na vida profissional e valorização da liberdade e individualidade.

Mais recentemente, no bojo das lutas pela garantia dos direitos e respeito às diferenças, tem surgido uma outra configuração familiar, a chamada família homoparental, constituída por casais homossexuais com filhos biológicos ou não. Embora a discussão em torno do seu reconhecimento social e legal ainda seja muito polêmica e cercada de preconceitos (PERELSON, 2006; FONSECA, 2008) é, sem dúvida, mais uma possibilidade de família que se anuncia, dentro da pluralidade de arranjos que hoje convivem com o ainda hegemônico modelo de família nuclear constituído pelo casal heterossexual com filhos biológicos.

No que se refere às mudanças nas relações de gêneros dentro da família é inegável que houve avanços, principalmente na reorganização do poder e autoridade, à medida que a mulher se profissionalizou e ampliou sua participação no mercado de trabalho. Ao se tornar coprovedora da família ela aumentou seu poder de negociação e o homem teve que se adaptar, até mesmo porque já não quer ou não consegue mais ser o único provedor da família (OLIVEIRA, 2005). Mas são avanços ainda muito tímidos se considerarmos que a desigual, divisão sexual de tarefas e responsabilidades domésticas ainda persistem nos dias de hoje. Mesmo trabalhando fora e investindo na carreira profissional, tanto quanto os homens, as mulheres continuam sendo as principais responsáveis pela educação dos filhos, cuidados da família e administração da casa. E os homens, em geral, apenas “ajudam” quando podem ou 
após muita cobrança por parte das companheiras (ARAUJO, 2008). Pesquisas brasileiras mostram que as mulheres gastam em média 27,2 horas semanais com atividades domésticas, enquanto os homens gastam apenas 10,2 horas (BRUSCHINI, 2007). Além disso, quando realizam alguma tarefa doméstica, eles preferem atividades mais valorizadas como fazer compras, auxiliar os filhos nas tarefas escolares ou levá-los para passear, e, nunca uma atividade rotineira como lavar ou passar (SORJ, FONTES, MACHADO, 2007).

Segundo dados do IBGE (PNAD, 2008) a participação das mulheres no mercado de trabalho brasileiro cresceu de 42,0\% para 47,2\% entre 1998 e 2008, mas isso não alterou a desigual divisão das tarefas domésticas. Entre as que têm emprego, 87,9\% cuidam dos afazeres do lar, enquanto entre os homens esse número chega a 46,1\%. O número médio de horas semanais dedicado a tarefas domésticas pelas mulheres é de 20,9\% e para os homens 9,2\%. Além disso, o aumento da presença feminina no mercado de trabalho impulsionou o crescimento de famílias com chefia feminina - mais de 1/3 das famílias brasileiras são chefiadas por uma mulher.

No entanto, apesar da sobrecarga feminina ainda presente na distribuição das tarefas domésticas e familiares, pode-se dizer que houve avanços concretos na garantia de direitos e democratização do poder e responsabilidades dentro da família, já incorporados na Constituição de 88 e em revisões posteriores da legislação. Exemplos mais recentes são a guarda compartilhada e a ampliação da licença paternidade, duas medidas, garantidas na lei, que podem efetivamente contribuir para uma mudança de mentalidade e desconstrução dos estereótipos de gênero que elegem a mulher como a única ou principal responsável pelo cuidado dos filhos e tarefas domésticas.

\section{Considerações finais}

Ao longo do texto destacamos as principais mudanças nos valores, comportamentos e formas de organização da família brasileira ocorridas sob a influência da modernização capitalista e dos ideários libertários em defesa da democracia, da liberdade e igualdade, e reconhecimento dos direitos humanos e individuais. De forma não exaustiva procuramos resgatar os principais marcos dessas mudanças ao longo do tempo, com destaque para o período pós-1964 quando se deu a aceleração do processo de modernização capitalista e a revolução de valores que levou à crise da família nos anos 1970 e à sua passagem, nas 
décadas seguintes, do tradicional modelo hierárquico e autoritário para outras formas de organização familiar mais democráticas e igualitárias.

A modernização capitalista implantada pelo governo militar no pós-64, embora conservadora, colocou as bases para as grandes transformações sociais, econômicas e culturais que se seguiram em meio a muitas contradições, crises e avanços no desenvolvimento do país, com forte impacto na vida social e familiar. Dentre eles a expansão da indústria cultural e de serviços e ampliação das oportunidades de trabalho que impulsionaram a profissionalização e inserção da mulher no mercado de trabalho e, consequentemente, uma revisão nos papéis de gênero e nas relações de poder dentro da família. Tais mudanças no papel da mulher da sociedade e na família atendiam a antigas reivindicações feministas e democráticas.

Convém ressaltar que cada um desses fatores não pode ser tomado individualmente como determinante único ou principal das mudanças da família. Cada um deve ser tomado na imbricação com os demais e sempre de forma contextualizada levando em conta a relação dialética entre eles. Dito de outra forma, não se pode dizer, por exemplo, que a modernização capitalista, o feminismo ou a democracia foram por si os responsáveis pelas mudanças da família, mas sim que todos eles contribuíram para isso em maior ou menos intensidade, de acordo com o momento histórico e/ou perspectiva de análise.

Como se sabe, as conquistas da modernização capitalista, do feminismo e da democracia não ocorreram (e ainda não ocorrem) da mesma maneira nos diferentes segmentos e contextos sociais e culturais. No Brasil elas são mais acessíveis aos segmentos médios urbanos mais intelectualizados, onde é mais visível o processo de democratização das relações pessoais e familiares, no questionamento das desigualdades de gênero e revisão dos papéis tradicionalmente atribuídos ao masculino e ao feminino.

Concluindo, reafirmamos a importância de refletirmos sobre todas essas mudanças na transformação da nossa vida pessoal e familiar. Concordamos com Giddens (2000) quando diz que de todas as mudanças que estão acontecendo no mundo contemporâneo uma das mais importantes é a democratização das relações pessoais - no casamento e na família, nos papéis de gênero e na sexualidade. Elas produzem uma verdadeira revolução no modo como pensamos sobre nós mesmos e no modo como estabelecemos laços e ligações com os outros. A incorporação dos princípios democráticos à vida cotidiana é tão importante quanto à democracia política e social para o aperfeiçoamento de nossas vidas, pois melhora a qualidade dos relacionamentos conjugais e familiares e demais relações sociais. A igualdade não é 
apenas um princípio essencial à democracia, ela é relevante para a felicidade e para a realização pessoal.

\title{
FAMILY, CAPITALIST MODERNIZATION AND DEMOCRACY: returning to some milestones of the longstanding debate on the transformations of the family in Brazil
}

\begin{abstract}
The article analyzes the transformation of the family in Brazil under the influence of capitalist modernization and libertarian social movements in defence of democracy, of freedom and equality, of the recognition of differences, and of human and individual rights. In a non-exhaustive manner it aims to touch on some of the major milestones in these changes, with special emphasis on the post-1964 period. In this period, modernizing processes accelerated and a revolution in values took place, leading to the crisis of the family of the 1970s and its passage over the following decades, from the traditional authoritarian and hierarchical model to other more democratic and egalitarian forms of organization.
\end{abstract}

Keywords: Family. Capitalist Modernization. Democracy. Feminism.

\section{Referências}

ALMEIDA, M.C.L. Em busca da igualdade: um estudo de casais de camadas médias urbanas de Recife. Dissertação de Mestrado. Programa de Pós-Graduação em Antropologia/UFPE, Recife, 1988.

ALVES, D. O desencontro marcado. Belo Horizonte: Interlivros, 1973.

ARAUJO, M.F. Família igualitária ou democrática? As transformações da Família no Brasil. Dissertação de Mestrado. Programa de Pós-Graduação em Psicologia Clínica. PUC/SP, São Paulo, 1993.

ARAUJO, M.F. Casamento e Sexualidade. A revisão dos mitos na perspectiva de gênero. Tese de Doutorado. Programa de Pós-Graduação em Psicologia Social. IPUSP/SP, São Paulo, 1999.

ARAUJO, M. F. Família, Democracia e Subjetividade. Org \& Demo (UNESP. Marília), v. 9(1/2), p. 111-124, 2008.

AZZI, R. Família e valores no pensamento brasileiro (1870-1950). In: RIBEIRO, I. (org) 
Família e Valores. São Paulo: Loyola, 1987(p.85-120).

BRUSCHINI, M.C.A. Trabalho e gênero no Brasil nos últimos dez anos. Cadernos de Pesquisa, v.37, n.132, p.537-572, 2007.

CERRONI, U. La relación hombre-mujer en la sociedad burguesa. Barcelona: Akal, 1975. COSTA, J.F. Ordem Médica e Norma Familiar. Rio de Janeiro: Graal, 1989.

COUTINHO, C. N. Democracia e socialismo. São Paulo: Cortez, 1992.

COUTINHO, C.N. A época neoliberal: revolução passiva ou contra-reforma? Comunicação apresentada no “5ºminário Internacional Gramsci”. Marília (SP), Faculdade de Filosofia e Ciências/UNESP, agosto de 2007.

DA MATTA, R. A família como valor: considerações não familiares sobre a família brasileira. In: ALMEIDA, A.M. (org) Pensando a família no Brasil. Da Colônia à modernidade. Rio de Janeiro: Espaço e Tempo, 1987(p.115-136).

DOMINGOS, J.M. A dialética da modernização conservadora e a nova história do Brasil. DADOS, v.45, n.3, p. 459-482, 2002.

FAUSTO, B. A revolução de 1930. São Paulo: Brasiliense, 1981.

FERNANDES, F. A Revolução Burguesa no Brasil. Rio de Janeiro: Zahar, 1981.

FIGUEIRA, S.A. O moderno e o arcaico na nova família brasileira: notas sobre a dimensão invisível na mudança social. In: Figueira, S.A. Uma nova família? O moderno e o arcaico na família de classe média brasileira. Rio de Janeiro: Zahar, 1987 (p.11-30).

FOLHA DE S.PAULO. Família Brasileira. Pesquisa Nacional do Datafolha. Publicada em 7 de outubro de 2007, Cad. Especial.

FONSECA, C. Homoparentalidade: novas luzes sobre o parentesco. Rev. Estudos Feministas, v. 16, no. 3, p.769-783, 2008.

FREIRE, G. Casa Grande \& Senzala: formação da família brasileira sob o regime da economia patriarcal. São Paulo: Ed. Global, 2008 (51. edição).

FURTADO, C. O Brasil Pós-Milagre. São Paulo: Paz e Terra, 1982.

GIDDENS, A. O mundo em descontrole. Rio de Janeiro: Record, 2000.

HABBERMAS, J. Modernismo, Pós-Modernismos ou Anti-Modernismo? Arte em Revista, n.7, ano 5, CEAC/SP, agosto, 1983.

HEILBORN, M.L. Dois é par. Gênero e identidade sexual no contexto igualitário. Rio de Janeiro: Garamond, 2004.

KINZO, M. D'A. democratização brasileira: um balanço do processo político de transição. São Paulo Perspec. v.15 n.4, p. 3-12, 2001. 
MARX, K.; ENGELS, F. Manifesto do Partido Comunista. São Paulo: Global Editora, 1990, $8^{\text {a. }}$ Ed.

MENDONÇA, D. A vitória de Tancredo Neves no Colégio Eleitoral e posição política dos semanários Veja e Isto É. ALCEU, v.5, n.10, p. 164-185, 2005.

MOORE JUNIOR, B. As origens sociais da ditadura e da democracia: senhores e camponeses na construção do mundo moderno. São Paulo: Martins Fontes, 1975.

MURICY, K. O indivíduo e a sociedade em Machado de Assis. In: ALMEIDA, A.M. (org) Pensando a Família no Brasil. Da colônia à modernidade. Rio de Janeiro: Espaço e Tempo, 1987 (p. 69-78).

OLIVEIRA, F. Além da Transição/Aquém da Imaginação. Novos Estudos Cebrap, 12, p.2-15, 1985.

OLIVEIRA, Z.L.C. A provisão da família: redefinição ou manutenção de papéis? In: ARAUJO, C.\& SCALON, C. (orgs) Gênero, família e trabalho no Brasil. Rio de Janeiro: Editora FGV, 2005 (p. 123-147).

ORTIZ, R. A Moderna Tradição Brasileira. São Paulo: Ed. Brasiliense, 1988.

PEREIRA, L.C.B. Desenvolvimento e Crise no Brasil (1930-1983). São Paulo: Brasiliense, 1985.

PERELSON, S. A parentalidade homossexual: uma exposição do debate psicanalítico no cenário francês atual. Rev Estudos Feministas, v.13, n.3, p. 709-730, 2006.

QUINTEIRO, M.C. Casados não casados: uniões consensuais nas camadas médias e populares. Textos NEPO, 19, Campinas/UNICAMP, 1990.

REIS, E.P. Elites Agrárias, State-Building e Autoritarismo. DADOS, v.25, n. 3, p.331-348, 1982.

RIOS, M.G; GOMES, I.C. Casamento contemporâneo: revisão bibliográfica acerca da opção por não ter filhos. Estudos de Psicologia (Campinas), v.26, p.215-226, 2009.

RUSSO, J. A difusão da psicanálise nos anos 70: indicações para uma análise. In: Ribeiro, I. (org) Família e Valores. São Paulo: Loyola, 1987(p.189-204).

SALEM, T. Famílias de camadas médias: uma revisão da literatura. Boletim do Museu Nacional, n.54, Rio de Janeiro, Museu Nacional/UFRJ, 1986.

SALEM, T. O casal grávido. Disposições e dilemas da parceria igualitária. Rio de Janeiro: Editora FGV, 2007.

SAMARA, E.M. Tendências atuais da história da família no Brasil. In: Pensando a família no Brasil: Da colônia à modernidade. Rio de Janeiro: Espaço e Tempo, 1987(p.25-36). 
SCHWARZ, R. Ao Vencedor as Batatas. São Paulo: Ed. Duas Cidades, 1988.

SHINN, T. Desencantamento da modernidade e da pós-moderndade: diferenciação, fragmentação e a matriz de entrelaçamento. Scientiae Studia. São Paulo, v.6 (1), p. 43-81, 2008.

SKIDMORE, T. Brasil: De GETÚliO A CASTELO. São Paulo: Paz e Terra, 1979.

SORJ, B.; FONTES, A.; MACHADO, D.C. As políticas e as práticas de conciliação entre família e trabalho no Brasil. Cadernos de Pesquisa, v.37, n.132, p.573-594, 2007.

VELHO, G. Aliança e casamento na sociedade moderna: separação e amizade em camadas médias urbanas. Boletim do Museu Nacional, n.39, Rio de Janeiro/UFRJ, 1981.

WERNECK VIANNA, L. Liberalismo e Sindicato no Brasil. Rio de Janeiro: Paz e Terra, 1976. 